\title{
ROI EN MEDIOS SOCIALES: CAMPAÑAS DE MARKETING EN
} BIBLIOTECAS

\section{Nieves González-Fernández-Villavicencio}

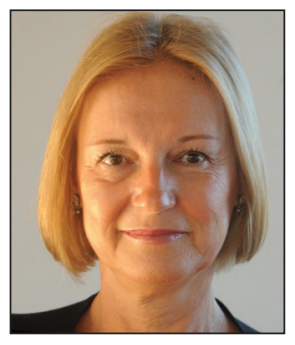

Nieves González-Fernández-Villavicencio es responsable de la biblioteca de la Facultad de Económicas y Empresariales de la Universidad de Sevilla y profesora-responsable del Área de Biblioteconomía y Documentación de la Universidad Pablo de Olavide (Sevilla). Doctora en sociedad del conocimiento por la Universidad de Salamanca, sus líneas de investigación se han centrado en el marketing digital y los medios sociales, las competencias digitales y los servicios de referencia presencial y virtual. Es autora del blog Bibliotecarios 2020.

http://orcid.org/0000-0001-8940-7429

Universidad de Sevilla, Facultad de Económicas y Empresariales, Biblioteca Ramón y Cajal, 1. 41018 Sevilla, España nievesg@us.es

\section{Resumen}

Las organizaciones deben incluir los medios sociales en su plan de marketing digital para obtener unos beneficios que los expertos han asociado tradicionalmente a retornos no ROI como el ROI social, el IOR (Retorno en relaciones), ROC (Retorno en colaboración), ya que se miden en términos de visibilidad, influencia, reputación, fidelización o interacción con las audiencias pero no en conversiones. Se aborda la relación entre marketing digital y bibliotecas y se plantea la posibilidad de obtener un ROI en términos de conversión a través de campañas de marketing correctamente planificadas. Se revisan los conceptos relacionados con marketing digital y medios sociales y su uso por las empresas, organizaciones y bibliotecas para obtener cualquier tipo de ROI. Se describen los beneficios del marketing para las bibliotecas y se presentan tres casos de estudio de campañas en bibliotecas universitarias españolas, en los que se demuestra cómo han conseguido sus objetivos de conversión centrados en un mayor uso de la colección o de los servicios, en un plazo estipulado de tres meses, incluso superando las expectativas.

\section{Palabras clave}

Marketing digital; Medios sociales; Marketing en medios sociales; Bibliotecas; Bibliotecas universitarias; Rentabilidad; ROI; Retorno de la inversión; Influencia; Reputación; Fidelización; Campañas de marketing.

\section{Title: Social media profitability: marketing campaigns in libraries}

\begin{abstract}
Organizations should include social media marketing as a part of a digital marketing plan. Traditionally the benefits obtained from social media marketing have been associated with not economical ROI, i.e., social ROI (return on influence, return on relationships, return on collaboration, reputation, branding, etc.). This study addresses the use of digital marketing campaigns by libraries for social profitability, i.e., obtaining conversions to more readers and more circulation. Concepts related to digital marketing and social media marketing, and the way different types of organizations, business and libraries use them in order to get ROI, are reviewed. The marketing benefits for libraries are presented, along with three case studies about promotion and marketing campaigns in university libraries in Spain that show how libraries can improve and increase the use of their services and products beyond their expectations with a marketing campaign of only three months.
\end{abstract}

\section{Keywords}

Digital marketing; Social media; Social media marketing; Profitability; ROI; Return on investment; Influence; Reputation; Loyalty; Branding; Libraries; Academic libraries; Marketing campaigns.

González-Fernández-Villavicencio, Nieves (2015). "ROI en medios sociales: campañas de marketing en bibliotecas". El profesional de la información, v. 24, n. 1, enero-febrero, pp. 22-30.

http://dx.doi.org/10.3145/epi.2015.ene.03

1. ¿Para qué son buenos los medios sociales en un plan de marketing digital?

Internet se ha convertido en el mayor mercado mundial de transacciones de bienes y servicios, planteando cuatro gran- des áreas de atención: la explosión de los datos (big data), los medios sociales, las proliferación de canales, y los cambios de los perfiles demográficos. Los tres primeros afectan al marketing digital (Leeflang et al., 2014). 
El uso de medios sociales por las empresas no para de crecer $^{1}$ así como la inversión en publicidad en estos medios ${ }^{2}$. 2014 ha sido denominado el año de lo social, de la aceptación social, debido a que la mayoría de empresas están invirtiendo en marketing en medios sociales. La consultora eMarketer estima en su informe Social media advertising: seven trends for 2014, que en 2015 el 89\% de las empresas utilizarán los medios sociales para sus actividades de promoción y marketing.

\section{4 ha sido denominado el año de la aceptación social, debido a que la ma- yoría de empresas están invirtiendo en marketing en medios sociales}

Sin embargo, con las funciones que actualmente presentan, los medios sociales no parecen la vía más adecuada para efectuar transacciones, la denominada conversión -convertir visitantes en clientes o usuarios-, y su utilidad no va a ser para generar retorno económico (Heggestuen, 2013), como muestran las abundantes estadísticas que se encuentran en la $\operatorname{Red}^{3}$. Habrá que comprobar si los botones de "compra" que se están implementando en Facebook o Twitter lo corroboran ${ }^{4}$.

Donde sí hay consenso es en la bondad de estos medios para monitorizar las audiencias y la competencia, para construir la marca y mejorar la reputación, alcanzar una mayor influencia sobre la lealtad de los seguidores (Mehrabi; Islami; Aghajani, 2014) y establecer y mantener relaciones consistentes con los clientes: el retorno en relaciones o impact on relationship y el ROI social (SROI). Sin embargo, estudios recientes como el de la consultora eMarketer (2013) indican que las empresas están segmentando mejor su publicidad, es decir, dirigiéndola a un público objetivo más específico y de esta forma están obteniendo un mejor ROI.

Las ventas en el entorno digital están aumentando de forma continuada, en gran medida a través de dispositivos móviles. La mayoría de compras se realizan tras influencia onli$n \mathrm{e}^{5}$. Los medios sociales están impactando en el proceso de compra, ya sea porque el cliente pulse directamente en la publicidad de Facebook y realice la compra o porque vea un pin en Pinterest y acabe comprando el producto en una tienda física una semana más tarde 6 . Es lo que se conoce como efecto ROPO (research online, purchase offline). El usuario busca en internet lo que necesita, lo valora y va después al espacio físico de la tienda a adquirirlo, o en el caso de la biblioteca, a usar sus colecciones y servicios (GonzálezFernández-Villavicencio, 2014a). Recientes estudios ponen de manifiesto cuáles son los medios sociales más rentables, y se confirma la primacía de Facebook, Twitter y Pinterest para generar compras inmediatas ${ }^{7}$.

En una estrategia de marketing la web social ha llegado a ser crucial y se puede integrar desde dos aproximaciones (Constantinides, 2014):

1. Pasiva: se monitorizan todos los medios sociales para oír la voz de los usuarios y lo que dicen de la marca. La empresa puede conocer mejor a sus clientes, espiar la competencia, detectar las necesidades de los usuarios o identificar tendencias. La figura del chief listening officer que realiza esta tarea, se considera sin embargo demasiado pasiva para ser efectiva (Loria, 2014).

2. Activa: se utilizan estos medios como herramienta de comunicación y canal de venta directa, para la adquisición de clientes y su fidelización. Para ello hay que personalizar la experiencia del usuario e incentivar su creatividad. A su vez esta aproximación se divide en otras dos:

- Uso de las aplicaciones de la web social para las relaciones públicas y con fines de comunicación, aunque con bastante frecuencia de forma unidireccional, sin interacción de los usuarios.

- Como forma de conseguir el engagement (compromiso y fidelidad) del público objetivo, personalizando la experiencia online del usuario, focalizando los contenidos que pueden ser de interés para ese colectivo específico y ofreciéndoles los servicios y productos que necesitan porque cubren una necesidad concreta.

En esta última aproximación basamos este trabajo.

Las bibliotecas necesitan del marketing para hacerse visibles dentro y fuera de su organización, para demostrar su valor y rentabilidad para la sociedad y la organización de la que dependen

\section{Bibliotecas y marketing}

Aunque existe abundante bibliografía sobre marketing y bibliotecas, esta relación no ha sido siempre bien entendida, incluso hoy día no todos los bibliotecarios ven con buenos ojos la idea de llevar a cabo acciones que impliquen técnicas de marketing, que tengan connotaciones de "venta" para las bibliotecas (McClelland, 2014).

En el trabajo de Marcos-Blázquez (2013) sobre bibliotecas de escuelas de negocio, en las que la cultura del marketing debería estar bien asentada, de los 50 centros participantes en el estudio, 43 no tenían plan de marketing.

El marketing es vital para las bibliotecas por varios motivos (Polger; Okamoto, 2013):

- para asegurar su permanencia, por restricciones presupuestarias y falta de financiación;

- para construir su imagen de marca dentro y fuera de los medios digitales; y

- por la creciente pérdida de visibilidad.

Los centros bibliotecarios necesitan del marketing para hacerse visibles dentro y fuera de su organización, para demostrar su valor y rentabilidad para la sociedad y la organización de la que dependen ${ }^{8}$. El marketing es el puente entre lo que las bibliotecas ofrecen y lo que los usuarios esperan y hay que estar dispuestos a comunicar de forma constante lo que los bibliotecarios son capaces de hacer para responder a las necesidades de los usuarios (Thomsett-Scott, 2014).

El proceso de marketing no consiste simplemente en vender, sino en investigar qué necesita el cliente para poder 
crear productos adecuados para él; es un intercambio de información entre proveedores y/o consumidores del producto o servicio, para mejorar éstos y adaptarlos a lo que demanda el mercado (Beltrán-Nava, 2012). Los contenidos que se promocionan a través del marketing tienen que estar muy personalizados para que sean efectivos, en caso contrario se rechazan o ignoran.

\section{El plan de marketing digital y los medios sociales}

El plan incluye los canales de medios sociales y por lo tanto define y controla la actividad en estos medios de la organización. Debe contribuir a los objetivos del plan estratégico general con participación y responsabilidad de todos los empleados, sea cual sea su área de trabajo en la organización, porque a todos deben afectar en mayor o menor medida las actuaciones definidas en el mismo (González-FernándezVillavicencio, 2013).

\section{El plan de marketing en medios sociales tiene que estar integrado y contribuir a los objetivos del plan estratégico gene- ral con participación y responsabilidad de todos los empleados}

La implementación de un plan de marketing digital incluye los siguientes pasos, con especial referencia a los canales sociales:

1. Establecer los objetivos que se quieran alcanzar. "No permitas que tu biblioteca esté en los medios sociales sin un objetivo" (Solomon, 2013).

2. Segmentar el target, el público objetivo, el grupo específico de usuarios para el que se ha establecido ese objetivo y para el que se van a implementar una o varias aplicaciones de la web social. La personalización de los servicios representa hoy día uno de los mayores retos y oportunidades de negocio y lleva a ofrecer una información personalizada y adaptada a cada tipo de usuario, cuando el usuario la necesite y no en el momento en el que se produce (Kesselman, 2014).

3. Seleccionar el canal. Thomsett-Scott (2014) ofrece una variada selección de aplicaciones y servicios de la web social que las bibliotecas están utilizando como canales de marketing específicos y la forma en la que los utilizan.

4. Diseñar un plan de acción especificando: acciones a realizar, contenidos de los que se va a hablar y de dónde se van a extraer o servir de inspiración, fuentes, periodicidad o frecuencia de publicación, quién los creará, y técnicas para conseguir engagement con los usuarios.

5. Establecer un sistema de evaluación en función de los indicadores de seguimiento de las métricas que se han utilizado. Estos indicadores van a permitir realizar un diagnóstico de la situación para la toma de decisiones. Para ello se necesitan métricas e indicadores, KPIs (key performance indicators o indicadores clave del rendimiento), que ilustran de la efectividad de la acción en relación con el objetivo. Una lista de métricas de utilidad para las bibliotecas y servicios de información puede encontrarse en el trabajo de GonzálezFernández-Villavicencio (2014b). La toma de datos puede ser mensual -aunque se recomienda que sea semanal, y deben compararse con otros períodos de tiempo en los que no se han realizado estas campañas en los medios sociales. También se aconseja comparar los datos con los de la competencia, como pueden ser los de otras bibliotecas de características similares.

Muchas aplicaciones en la Web permiten tomarle el pulso a las herramientas de la web social -además de las que proporcionan las mismas aplicaciones-, como las que aparecen en Mapa mental de herramientas para monitorizar ${ }^{9}$.

6. Crear una política de uso de los medios sociales. MargaixArnal (2013) propone unas directrices de contenido para la elaboración de guías de usos y estilos pensadas para bibliotecas universitarias pero aplicables a cualquier organización.

7. Comunicar los resultados frecuentemente.

Los planes de acción tácticos que incluyen campañas de promoción forman parte del plan de marketing digital. En el ámbito de las bibliotecas se ha demostrado que tras una campaña de promoción bien orquestada utilizando los medios sociales, se consigue aumentar el uso de los productos y servicios de la biblioteca, es decir, su rentabilidad. Las campañas de la New York Public Library son un buen ejemplo. En ellas no sólo aumenta el número de interacciones de sus usuarios en los medios sociales sino también, por ejemplo, el número de carnets de la biblioteca ${ }^{10}$. Otro ejemplo son las campañas de The Montana State University (MSU) Library, con Facebook y un pequeño presupuesto para promocionar determinados posts, por lo que se consigue mayor visibilidad en los timelines de los seguidores que sean público objetivo de la campaña (Young et al., 2014).

A continuación se presenta la evolución y los resultados obtenidos en tres campañas de promoción llevadas a cabo en bibliotecas universitarias españolas, en las que se aportan resultados que demuestran cómo las bibliotecas han alcanzado los objetivos específicos fijados previamente de un mayor uso de recursos y servicios, tras una adecuada planificación y desarrollo de cada una de sus etapas.

\section{No permitas que tu biblioteca esté en los medios sociales sin un objetivo}

\section{Campañas de promoción en medios sociales en tres bibliotecas universitarias}

Las campañas son acciones (a veces es sólo una) que se llevan a cabo durante un período de tiempo determinado y se enfocan a un tema particular con características propias muy elaboradas. Como hemos visto, forman parte del plan de marketing digital de la organización, del que mana la estrategia a seguir.

El objetivo que se plantea es diseñar y llevar a cabo una campaña de promoción específica para cada biblioteca universitaria de la muestra, que convierta las acciones que se están realizando en la web social en beneficios rentables 
para la institución, o sea, un aumento del uso de los recursos o servicios. Se quería demostrar que los recursos invertidos en estos medios por parte del personal bibliotecario, de los cuales el factor tiempo es el más significativo (Polger; Okamoto, 2013), presentan un coste relativamente bajo si lo comparamos con los beneficios que pueden obtener con el aumento en el uso de sus recursos y servicios.

Se han seleccionado tres bibliotecas universitarias que destacan por su actividad en los medios sociales y que han aceptado participar en este estudio, aportando su tiempo y los datos de resultados. Se ha tenido en cuenta su diferente localización geográfica, un tamaño representativo de la media y su carácter presencial o no. De esta forma consideramos que la muestra es suficientemente diversa aunque su número sea escaso, por lo que contemplar un número mayor de elementos de la muestra debería ser el objetivo de futuras investigaciones.

Las tres bibliotecas son:

- Biblioteca general Reina Sofía de la Universidad de Valladolid;

- Biblioteca universitaria de Huelva;

- Sede central de la Biblioteca de la UNED.

Se ha trabajado de forma individual con cada centro, con una misma metodología como se observa en la tabla 1, que resume la estrategia y su desarrollo. Se definieron los objetivos de la campaña en función de los objetivos de marketing digital que propuso cada una. Esto llevó a identificar el segmento de usuarios al que dirigir la campaña así como los canales más adecuados.

Los detalles de definición y seguimiento del plan de acción se documentaron, llevándose un protocolo de seguimiento y control de resultados.

La personalización de los servicios lleva a ofrecer una información individualizada y adaptada a cada tipo de usuario cuando éste la necesite

Las características comunes de la estrategia de las tres campañas fueron:

- Cada biblioteca propuso su objetivo específico emanado de su estrategia de marketing digital, a conseguir en el mismo período de tiempo, desde el 1 de noviembre de 2013 hasta el 31 de enero de 2014.

- Este período incluye las vacaciones de Navidad, época de menor actividad en la vida de la comunidad universitaria, en la que se cierran muchos centros y no se puede hacer seguimiento de la actividad.

- Las bibliotecas han utilizado los canales en medios sociales que ya tenían disponibles y orientados al público objetivo que se había seleccionado, fundamentalmente Facebook y Twitter, pero también Pinterest y YouTube y otros como el correo-e.

- Las tres bibliotecas son muy activas en medios sociales, con elevadas tasas de interacción y participación de sus usuarios por encima de la media del resto de las biblio- tecas españolas (según los estudios de la Biblioteca de la Universidad de Zaragoza ${ }^{11}$ y Martín-Marichal, 2013).

- Las métricas que se han utilizado para medir la eficacia de la estrategia proceden de cada una de las aplicaciones que se han utilizado en cada campaña y se describen en los apartados siguientes. Básicamente se han monitorizado los datos procedentes de las aplicaciones y sistemas de gestión de las bibliotecas para contabilizar el uso de los recursos, que darían los datos de conversión, pero también los procedentes de los medios sociales que aportan el nivel de participación o engagement, así como los datos que miden el tráfico a la web e indican la fidelización de la audiencia. El cuadro de métricas procede del trabajo de González-Fernández-Villavicencio et al. (2013).

- En todos los casos se han superado, a veces con creces, los objetivos definidos.

En la tabla 1 se resumen las etapas del diseño de la campaña en cada biblioteca, así como el desarrollo de su estrategia y tácticas y los resultados obtenidos.

Google analytics permite conocer qué medios/formatos/contenidos ofrecen mejores resultados y se deben trabajar más

\subsection{Campaña en Google analytics de la Biblioteca ge- neral Reina Sofía de la Universidad de Valladolid}

Utilizar esta herramienta permite conocer los medios, formatos y contenidos que ofrecen mejores resultados y se deben trabajar más ${ }^{12}$. Mediante etiquetas que se añaden al URL, se identificó la procedencia de los enlaces entrantes, ya fueran por correo-e, Facebook o Twitter, además del nombre de la campaña. Las visitas procedentes del correo-e son las que menos tasa de rebote han tenido, las visitas procedentes de Twitter fueron las que más tiempo estuvieron en la web y más páginas visitaron y las de Facebook son las menos pertinentes, las que menos páginas visitan y menos tiempo permanecen.

No se han podido obtener los datos de enero de 2014, por lo que se ofrece la suma de las consultas a todos los ítems de los registros de los discursos de noviembre y diciembre de 2012 , que fue de 3.866, y la suma de los mismos meses en 2013, que fue de 5.017. Esto representa en esos dos meses de 2013 un aumento de un 29,8\% frente a 2012. En el gráfico 1 puede verse la diferencia de las consultas de los mismos meses en los dos años.

Estaban bien definidos el objetivo y el público objetivo, y se ha conseguido el objetivo propuesto. Sin embargo a pesar del poder de engagement de los canales en Twitter y Facebook de esta biblioteca, no han sido los adecuados para este objetivo ya que ese segmento no estaba en dos de los tres canales que se han utilizado para la promoción. De ahí que no se haya conseguido el nivel de participación de las demás bibliotecas, como se comprueba en la tasa de engagement o participación que ha sido de 0,1 en Facebook. Esto se ha obtenido aplicando la fórmula de Castelló-Martínez (2013), en la que se divide el número de interacciones en Facebook por el número de posts, y esto a su vez por el número de 
Tabla 1. Resumen de las campañas

\begin{tabular}{|c|c|c|c|}
\hline & $\begin{array}{c}\text { Biblioteca general Reina Sofía de la } \\
\text { Universidad de Valladolid }\end{array}$ & Biblioteca universitaria de Huelva & Biblioteca de la UNED. Sede central \\
\hline Objetivo & $\begin{array}{l}\text { Aumentar en un } 20 \% \text { el número de las con- } \\
\text { sultas a la colección de discursos de apertura } \\
\text { del repositorio UVaDOC, con respecto a los } \\
\text { datos de los mismos meses del año anterior } \\
\end{array}$ & $\begin{array}{l}\text { Incrementar el uso de la colección de DVD de la } \\
\text { Mediateca, en un } 20 \% \text {, en relación con los mismos } \\
\text { meses del año anterior }\end{array}$ & $\begin{array}{l}\text { Aumentar en un } 10 \% \text { el uso de Linceo+el busca- } \\
\text { dor integrado de recursos, en comparación con } \\
\text { la media anual }\end{array}$ \\
\hline $\begin{array}{l}\text { Público obje- } \\
\text { tivo }\end{array}$ & Investigadores de la Universidad de Valladolid & Estudiantes de la Universidad de Huelva & Estudiantes de la sede central de la UNED \\
\hline $\begin{array}{l}\text { Canales } \\
\text { sociales }\end{array}$ & Twitter y Facebook & Facebook & Facebook, Twitter, Pinterest y YouTube \\
\hline Otros canales & correo-e & & \\
\hline RRHH & Dirección de la biblioteca & Grupo Facebook de la biblioteca & Dos bibliotecarias \\
\hline $\begin{array}{l}\text { Plan de } \\
\text { acción: conte- } \\
\text { nidos }\end{array}$ & $\begin{array}{l}\text {-Lectura de los discursos, selección del } \\
\text { investigador en función del interés del tema } \\
\text { y envío del correo-e (DSI). } \\
\text {-Difusión por Facebook y Twitter. } \\
\text {-Los contenidos son los propios discursos } \\
\text { de apertura. }\end{array}$ & $\begin{array}{l}\text { Los contenidos han sido: } \\
\text {-Sinopsis de las películas } \\
\text {-Grandes diálogos de cine. Extractos de guiones } \\
\text { de películas. } \\
\text {-Concurso: las bibliotecas en el cine. Fotograma de } \\
\text { película en la que salga una biblioteca para que los } \\
\text { alumnos descubran qué película es. } \\
\text {-Aprende idiomas con el cine (películas Speak-Up) } \\
\text {-Película y su libro. Relación cine y literatura. } \\
\text {-Grandes actores. } \\
\text { Se solicita la colaboración de los alumnos en } \\
\text { Facebook para que realizaran resúmenes de las } \\
\text { películas. Esta idea no tuvo éxito. }\end{array}$ & $\begin{array}{l}\text {-Promoción directa del enlace a Linceo+. } \\
\text {-Se han creado vídeos en YouTube para promo- } \\
\text { cionarlo. Han participado alumnos en los vídeos } \\
\text { contando sus experiencias con el metabuscador. } \\
\text {-Se añaden mensajes relativos al beneficio de } \\
\text { su uso, opiniones de usuarios, guías de uso de } \\
\text { elaboración propia, recursos accesibles a través } \\
\text { de Linceo+ e imágenes de diseño propio. } \\
\text {-Se utilizan imágenes de películas famosas en } \\
\text { las que los personajes recomiendan el uso de } \\
\text { Linceo+ } \\
\text {-Tablero en Pinterest con todo el material gráfico } \\
\text { recopilado y las imágenes más divertidas para } \\
\text { promocionar Linceo+. }\end{array}$ \\
\hline $\begin{array}{l}\text { Influencia- } \\
\text { dores }\end{array}$ & $\begin{array}{l}\text { Localización de profesores/investigadores } \\
\text { influyentes que están interesados en los } \\
\text { temas de los discursos. }\end{array}$ & $\begin{array}{l}\text { Influenciadores } \\
\text { (facebookeros) relacionados con la universidad y el } \\
\text { cine (Aula Magna El periódico universitario, Festival } \\
\text { de cine iberoamericano, SACU, etc.). }\end{array}$ & \\
\hline $\begin{array}{l}\text { Calendario de } \\
\text { publicación }\end{array}$ & $\begin{array}{l}\text { En Facebook se realizó una publicación dia- } \\
\text { ria, alternando el conjunto de los discursos y } \\
\text { cada documento individualmente. } \\
\text { En Twitter, se publicó un tuit diario que se } \\
\text { enlazaba con la última entrada de Facebook. } \\
\text { La programación se realizaba semanal- } \\
\text { mente. }\end{array}$ & $\begin{array}{l}\text { Se programaron } 3 \text { publicaciones semanales en } \\
\text { Facebook: lunes, miércoles y viernes, pero el } \\
\text { número de publicaciones fue menor: en noviembre } \\
\text { se publicaron } 9 \text { posts, en diciembre } 3, \text { y en enero } \\
7 \text { relacionados con la promoción de la colección } \\
\text { de DVDs. }\end{array}$ & $\begin{array}{l}\text { Se programaron } 27 \text { tuits y } 15 \text { posts en Facebook } \\
\text { sobre Linceo+. }\end{array}$ \\
\hline Herramientas & $\begin{array}{l}\text { Google Calendar para planificar las entradas } \\
\text { y Hootsuite para programarlas. } \\
\text { Google Analytics para la creación y segui- } \\
\text { miento de los URLs reescritos o trackeados y } \\
\text { acortados, para la campaña personalizada. } \\
\text { Se utilizaron tres URLs para cada uno de } \\
\text { los discursos, que después la bibliotecaria } \\
\text { enviaría a los usuarios por cada uno de los } \\
\text { tres canales previstos: correo-e, Twitter y } \\
\text { Facebook. }\end{array}$ & $\begin{array}{l}\text { Una cuenta de bit.ly para todos los enlaces que } \\
\text { aparecen en la campaña de promoción. }\end{array}$ & $\begin{array}{l}\text { Google Calendar para planificar las entradas en } \\
\text { todos los canales (en Twitter, Facebook, Pinterest } \\
\text { y YouTube) y Hootsuite para programarlas. } \\
\text { Se han creado } 3 \text { vídeos y publicado en YouTube. } \\
\text { El } 5 \text { de diciembre crearon un tablero en Pinterest } \\
\text { con el material gráfico recopilado y las imágenes } \\
\text { más divertidas. } \\
\text { Han utilizado otros dos vídeos que tenían sobre } \\
\text { el uso de Linceo+, creados con Polimedia. }\end{array}$ \\
\hline Métricas & $\begin{array}{l}\text {-Número de visualizaciones y descargas de } \\
\text { la base de datos de los discursos UVaDOC } \\
\text { en relación con los mismos meses del año } \\
\text { anterior. De aquí se obtiene el porcen- } \\
\text { taje definido en el objetivo. Estos datos } \\
\text { proceden de la propia base de datos del } \\
\text { repositorio. } \\
\text {-Número de sesiones web en la base de da- } \\
\text { tos UVaDOC a través de los URLs trackeadas } \\
\text { de la campaña personalizada en Google } \\
\text { analytics (GA). } \\
\text {-Para determinar la eficacia de las activida- } \\
\text { des de promoción en Facebook y Twitter, } \\
\text { y a través del correo-e, se contabilizaron } \\
\text { las visitas, las veces que se ha clicado en el } \\
\text { enlace, los URLs trackeados, por cada uno } \\
\text { de los canales. Estos datos se obtienen de } \\
\text { GA opción Campañas. } \\
\text {-Nivel de participación e interacción de los } \\
\text { usuarios con estos contenidos en los medios } \\
\text { sociales. Para Facebook se han contabilizado } \\
\text { las interacciones y personas hablando de } \\
\text { esto; para Twitter, el número de RT. }\end{array}$ & $\begin{array}{l}\text { Métricas que se toman como evidencia. } \\
\text {-Datos procedentes del sistema de gestión de la } \\
\text { biblioteca, Millennium, sobre préstamos y reno- } \\
\text { vaciones de las películas en DVD, con carácter } \\
\text { mensual. } \\
\text {-Datos procedentes de las estadísticas de Face- } \\
\text { book, para ver la tasa de engagement. }\end{array}$ & $\begin{array}{l}\text { Datos obtenidos de las estadísticas de Linceo+, } \\
\text { informes de Hootsuite y estadísticas de Face- } \\
\text { book y YouTube. } \\
\text { Métricas que se toman como evidencia. } \\
\text {-Entradas en el metabuscador Linceo+ } \\
\text {-Interacciones de las publicaciones en Twitter. } \\
\text { Tasa de engagement. } \\
\text {-Interacciones en Facebook. Tasa de engage- } \\
\text { ment. } \\
\text {-YouTube: Número de reproducciones. }\end{array}$ \\
\hline Resultados & $\begin{array}{l}\text { Aumento del } 29,8 \% \text { de la suma de las con- } \\
\text { sultas de noviembre y diciembre de } 2013 \\
\text { en relación con los mismos meses de } 2012 \text {. }\end{array}$ & $\begin{array}{l}\text { Aumento de la suma de las transacciones de los } \\
\text { DVD, de los meses de noviembre y diciembre de } \\
2012 \text { y enero de } 2013 \text {, frente a los mismos meses } \\
\text { de } 2013 / 2014 \text {, de un } 54,6 \% \text {. }\end{array}$ & $\begin{array}{l}\text { El crecimiento de las visitas a Linceo+ en estos } \\
\text { meses en relación con la media es del } 42,4 \% \text {. }\end{array}$ \\
\hline
\end{tabular}




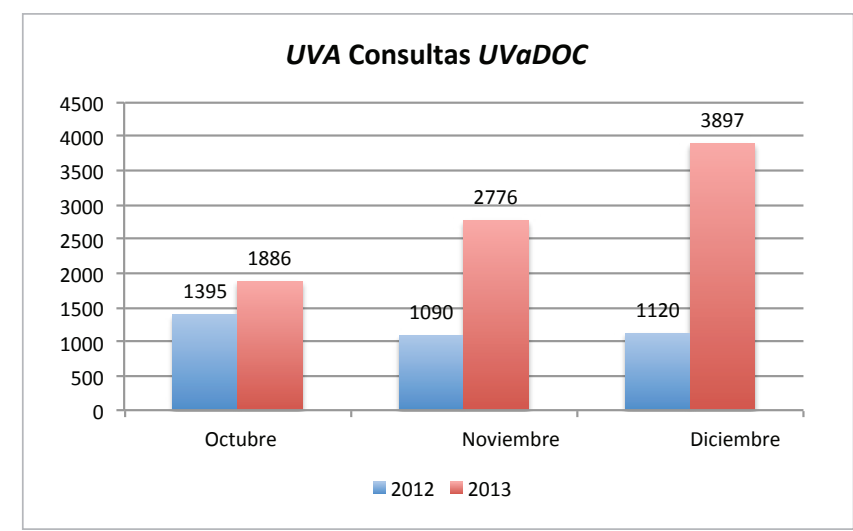

Gráfico 1. Consultas a UVaDOC

seguidores y se multiplica por cien. Probablemente sólo con el correo-e hubiera sido más efectivo por el tipo de público al que se dirige y sus niveles de uso de los medios sociales.

Los recursos humanos asociados han sido muy eficientes pero la carga de trabajo ha sido superior a los objetivos conseguidos. La bibliotecaria tenía que leerse los discursos antes de difundirlos y buscar el destinatario adecuado. La inversión realizada ha superado los beneficios.

\subsection{Uso de los vídeos en YouTube de la campaña de la Biblioteca de la UNED, sede central}

Ante la falta de series de datos amplias, se optó por comparar los resultados de los meses de la campaña con la media de uso de los meses para los que se contaba con datos.

Como se observa en el gráfico 2, las visitas a Linceo+ durante marzo de 2014, único mes para el que tenemos datos de 2013 y 2014 , suponen un $218 \%$ con respecto al mismo mes de 2013, pasando de 1.134 a 3.607 visitas. El crecimiento puede ser consecuencia de la campaña de promoción intensiva de los meses anteriores.

Se ha aplicado la tasa de engagement de la publicación que hace referencia a los posts sobre Linceo+ y se observa que la tasa sube a lo largo de los tres meses y oscila entre un 0,40 en noviembre y un 0,56 en enero, que se considera elevada.

En el gráfico 3 se puede ver el aumento en el volumen de las reproducciones de los vídeos sobre Linceo+ en YouTube.

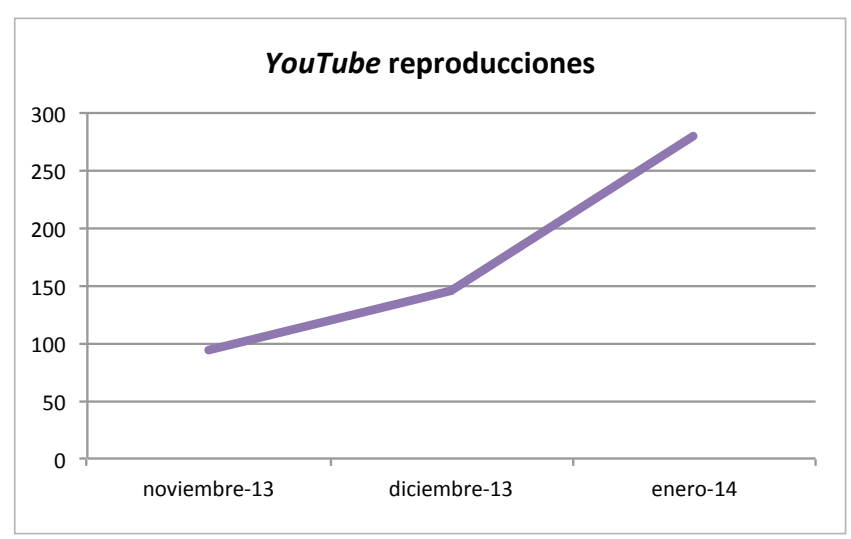

Gráfico 3. Evolución de las reproducciones de los vídeos sobre Linceo+ en YouTube

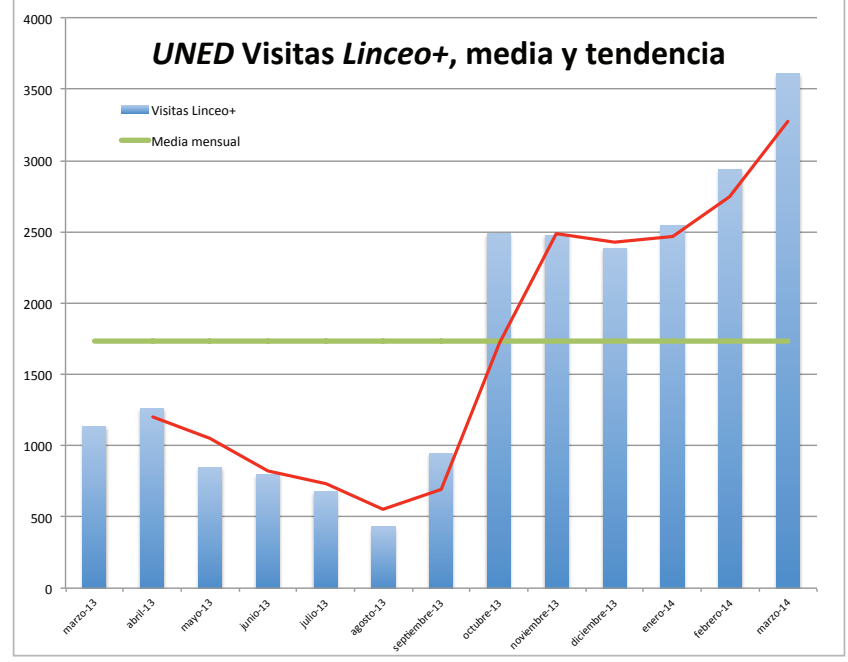

Gráfico 2. Visitas a Linceo+, media y tendencia

Podemos ver que se trata de una biblioteca muy activa en los medios sociales y que sabe como atraer la atención de los usuarios para que participen en las acciones que se proponen. El número de posts en Facebook y de tuits en Twitter ha sido el suficiente para no sobrecargar los timelines de los seguidores, y estos han respondido de forma participativa a casi todos los posts relativos a Linceo+. El tamaño de su audiencia hace que la tasa de interacción no sea muy alta, pero sube de forma continua durante la campaña de promoción.

Hasta hace poco, el uso de los medios sociales se asociaba sólo al logro de beneficios no económicos, vinculados a establecer relaciones con los clientes o mejorar la reputación de la marca

Se trata de una campaña que no debe tener fecha de finalización y que se debería programar para un tiempo mucho más largo del que ha durado en esta ocasión. El tipo de recurso que se ha promocionado exige una labor constante de difusión y dinamización que han realizado de forma muy creativa en esta biblioteca y no se han encontrado períodos de inactividad en la campaña.

El target debería segmentarse con más precisión, perfilar mejor las necesidades concretas de este colectivo e incidir en las ventajas que para los estudiantes, o el colectivo que se elija, representa el uso del metabuscador. Los contenidos deberían también diversificarse incluyendo trucos para usar Linceo+ más eficazmente, recomendaciones de profesores, ejemplos prácticos, etc.

\subsection{El equipo de facebookeros de la Biblioteca de Huelva}

Es evidente que los usuarios han respondido a la campaña desde Facebook que han Ilevado a cabo los bibliotecarios de la Universidad de Huelva. Los préstamos y renovaciones de los meses de la campaña, noviembre y diciembre, han supuesto el 25\% de toda la circulación de DVD de 2013. 
La tasa de engagement a la publicación en Facebook en los tres meses de estudio ha sido muy elevada ${ }^{13}$, entre un 0,48 en enero y un 0,88 en noviembre ya que la mayoría de las entradas tiene comentarios y muchos de ellos relativos al uso de la colección de DVD de la biblioteca. Por lo tanto, no sólo se está consiguiendo el objetivo de aumentar el uso de una parte de la colección, sino que además se está mejorando la reputación e influencia de la biblioteca.

Gracias a su potente equipo y canal de Facebook, el centro no va a tener problemas para conseguir cualquier objetivo que se proponga alcanzar en este medio. Con su ingenio ha sabido atraer al público y crear conversación y el compromiso que consiguen con los usuarios es muy elevado. Los bibliotecarios han respondido inmediatamente a las preguntas y comentarios de los usuarios, por lo que éstos siempre se han sentido parte de una conversación en tiempo real y que satisfacía sus necesidades y expectativas.

Una vez finalizado el plazo y conseguido el objetivo, las bibliotecas sólo tienen que mantener una actividad de recordatorio en estos medios para que el uso de los recursos no decaiga.

\section{Si se integran en un plan de marketing digital, los medios sociales son también buenos para conseguir un ROI que en las bibliotecas se traduce en un mayor uso de sus productos, servicios y espacios}

\section{Conclusiones}

El uso de los medios sociales se ha asociado al logro de beneficios no económicos o financieros, vinculados a su bondad para establecer relaciones con los clientes o mejorar la reputación o influencia de la marca. Además de estos fines deseables por las empresas y organizaciones incluidas las bibliotecas, cuando se integran en un plan de marketing digital, los medios sociales son también buenos para conseguir un ROI que, como sabemos, no sólo puede ser financiero y en el contexto de las bibliotecas, esa rentabilidad se traduce en un mayor uso de sus productos, servicios y espacios o del impacto de sus bibliotecarios. Se trata al fin y al cabo del negocio de la biblioteca, la razón por la que existe.

Por lo tanto, en el ámbito de los medios sociales, no se trata de saber únicamente si las bibliotecas los están usando o con qué fines o diferentes formas los utilizan, como puede ser la orientación del reciente estudio de Taylor and Francis (2014). Seguimos sin saber para qué estamos en los medios sociales, qué es lo que se quiere conseguir y cómo se va a medir el éxito o fracaso propio y de los competidores, con qué métricas o indicadores únicos y que se puedan compartir. En resumen, nos falta saber si el uso que se está ha- ciendo de estos medios en los que la empresa invierte cada vez más, es estratégico para conseguir los objetivos de la organización y contribuir a la misión de la biblioteca en la sociedad (Campbell; Lambright; Wells, 2014).

En este trabajo hemos querido demostrar la rentabilidad de la biblioteca en la web social, no traduciendo a términos financieros su rentabilidad, que podría haberse abordado con técnicas de valoración por contingencia tal y como lo han hecho otros autores como Taladriz-Mas (2013), sino que nos hemos basado en la consecución de los objetivos propuestos en sus planes de marketing mediante campañas de promoción. Es decir, el uso de los medios sociales es rentable siempre que se consigan los objetivos propuestos con una inversión razonable.

Se puede demostrar la rentabilidad de la actividad que las

\section{Es imprescindible que las bibliotecas asuman una cultura de marketing y se asignen recursos materiales para llevar a cabo campañas de marketing y recursos humanos dinámicos, creativos y en nú- mero suficiente}

bibliotecas realizan en estos medios siempre que obedezca a un plan de marketing digital, como hemos visto en ejemplos que aporta la literatura y en los tres casos de estudio de este trabajo. Para ello es imprescindible que las bibliotecas asuman una cultura de marketing, aunque tradicionalmente no haya sido considerada una actividad propia de las bibliotecas, y se asignen los recursos materiales necesarios para llevar a cabo campañas de marketing -incluso de pago- y recursos humanos dinámicos, creativos y en número suficiente.

\section{Notas}

1. Informe eEspaña de Orange 2014:

http://fundacionorange.es/fundacionorange/analisis/ eespana/e_espana14.html

2. Información accesible en: 
http://www.puromarketing.com/66/22993/marcasdestinaran-este-ano-mas-publicidad-social-media.html

3. Se pueden encontrar estadísticas de conversión en la sede de la empresa HubSpot:

http://www.hubspot.com/marketing-statistics

4. Más información en:

http://myofficemagazine.co.za/social-networks-to-roll-outbuy-buttons

5. Más información en la web Business Insider:

http://www.businessinsider.com/the-biggest-trends-in-ecommerce-2014-10

6. Más información en:

http://myofficemagazine.co.za/social-networks-to-roll-outbuy-buttons

7. Más información en el blog Bibliotecarios 2020:

http://www.nievesglez.com/2014/09/los-medios-socialesmas-rentables.html

8. Véase más información en:

http://tribuneci.wordpress.com/2013/11/18/le-marketingdans-les-bibliotheques-ou-comment-se-rendre-visible

9. Accesible en el mapa mental de Mindomo: http://www.mindomo.com/mindmap/8d1202fa445f4f41b8 $a 2 a 9456151 b c 1 b$

10. Más información en:

http://sherpablog.marketingsherpa.com/online-marketing/ nypl-social-media-marketing

11. Estudio de la Biblioteca de la Universidad de Zaragoza de 2012:

http://blog.biblioteca.unizar.es/general/el-indice-klout-enlas-bibliotecas-universitarias-espanolas

12. Página web de las campañas personalizadas de GA: https://support.google.com/analytics/answer/1033863?hl=es

13. Puede verse la media de las tasas de engagement de las empresas en la web de SocialBakers:

http://www.socialbakers.com/blog/2137-finding-the-rightengagement-rate-for-your-facebook-page-in-2014

\section{Bibliografía}

Beltrán-Nava, Tomás (2012). Promoción de los servicios bibliotecarios a través de las redes sociales de la internet. (Trabajo de licenciatura). Escuela Nacional de Biblioteconomía y Archivonomía de México.

http://eprints.rclis.org/17075

Campbell, David A.; Lambright, Kristina T.; Wells, Christopher J. (2014). "Looking for friends, fans, and followers? Social media use in public and nonprofit human services". Public administration review, v. 74, n. 5, pp. 655-663. http://dx.doi.org/10.1111/puar.12261

Castelló-Martínez, Araceli (2013). “El estudio del retorno de la inversión y el impacto en la relación de la comunicación empresarial y publicitaria en plataformas sociales: herramientas disponibles en el mercado". En: $2^{\circ}$ Congreso nacional sobre metodología de la investigación en comunicación, pp. 411-427.
http://rua.ua.es/dspace/bitstream/10045/28195/1/AE-IC_ Segovia_Araceli_Castello.pdf

Constantinides, Efthymios (2014). "Foundations of social media marketing". Procedia-Social and behavioral sciences, v. 148 , pp. $40-57$.

http://dx.doi.org/10.1016/j.sbspro.2014.07.016

eMarketer (2013). "The year of social? Nearly nine in 10 marketers will use social media marketing next year". eMarketer, 14 Nov.

http://www.emarketer.com/Article/Year-of-Social/1010386

González-Fernández-Villavicencio, Nieves (2013) “Métricas de la web social". Anuario ThinkEPI, v. 7, pp. 48-52.

http://www.thinkepi.net/metricas-de-la-web-social

González-Fernández-Villavicencio, Nieves (2014a). "El declive del ROI social". Anuario ThinkEPI, v. 8, pp. 264-268. http://www.thinkepi.net/el-declive-del-roi-social

González-Fernández-Villavicencio, Nieves (2014b). "The profitability of libraries using social media". En: TEEM' 14 Proceedings of the $2^{\text {nd }}$ Int l conf on technological ecosystems for enhancing multiculturality, pp. 561-566. New York: ACM. http://dx.doi.org/10.1145/2669711.2669956

González-Fernández-Villavicencio, Nieves; Menéndez-Novoa, José-Luis; Seoane-García, Catuxa; San-Millán-Fernández, María-Elvira (2013). "Revisión y propuesta de indicadores (KPI) de la biblioteca en los medios sociales". Revista española de documentación científica, v. 36, n. 1, e005. http://dx.doi.org/10.3989/redc.2013.1.919

Heggestuen, John (2013). "The decline of social ROI. How social media marketers are moving towards more basic, nofrills metrics". BI intelligence, Sept. 27.

Kesselman, Martin (2014). “On the horizon: customer engagement technology world conference in NYC: parallels with community engagement in libraries". Library hi tech news, v. 31, n. 2, pp. 1-4.

http://dx.doi.org/10.1108/LHTN-02-2014-0013

Leeflang, Peter S. H.; Verhoef, Peter C.; Dahlström, Peter; Freundt, Tjark (2014). "Challenges and solutions for marketing in a digital era". European management journal, v. 32, n. 1, pp. 1-12.

http://dx.doi.org/10.1016/j.emj.2013.12.001

Loria, Keith (2014). "Moving beyond the chief listening officer". eContent, 22 Oct.

http://www.econtentmag.com/Articles/News/News-Feature/ Moving-Beyond-the-Chief-Listening-Officer-100024.htm

Marcos-Blázquez, Amanda (2013). Metodología para la elaboración de un plan de marketing: propuesta de aplicación de las herramientas de marketing digital en la biblioteca IE. Tesis doctoral. Universidad Complutense de Madrid. http://eprints.ucm.es/20722

Margaix-Arnal, Dídac (2013). Los social media en las bibliotecas universitarias españolas: su presencia y las guías de usos y estilo. Trabajo fin de grado. Universidad de León. Grado en Información y Documentación.

https://buleria.unileon.es/handle/10612/2847 
Martín-Marichal, Carmen (2013). Las universidades y las bibliotecas universitarias en las redes sociales. Documento de trabajo. Universidad de Las Palmas de Gran Canaria.

http://acceda.ulpgc.es/handle/10553/10774

McClelland, Timothy (2014). "What exactly do you do here? Marketing-related jobs in public and academic libraries". Journal of library administration, v. 54, n. 5, pp. 347-367. http://dx.doi.org/10.1080/01930826.2014.946736

Mehrabi, Amir; Islami, Hossein; Aghajani, Mojtaba (2014). "The effect of social media marketing on customers' brand loyalty". Intl journal of academic research in business and social sciences, v. 4, n. 8, pp. 480-495.

Polger, Mark-Aaron; Okamoto, Karen (2013). “Who's spinning the library ? Responsibilities of academic librarians who promote". Library management, v. 34, n. 3, pp. 236-253. http://dx.doi.org/10.1108/01435121311310914
Solomon, Laura (2013). The librarian's nitty-gritty guide to social media. Chicago: ALA. ISBN: 9780838911600

Taladriz-Mas, Margarita (2013). "Los servicios de información y el retorno de la inversión: cómo llegar a conocerlo". El profesional de la información, v. 22, n. 4, pp. 281-285. http://dx.doi.org/10.3145/epi.2013.jul.01

Taylor \& Francis Group (2014). Taylor \& Francis Twitter party : use of social media in the library.

http://www.tandf.co.uk/journals/explore/librarian-twitterreport-2014.pdf

Thomsett-Scott, Beth C. (2014). Marketing with social media: A LITA guide. Chicago, Illinois: ALA TechSource. ISBN: 9781555709723

Young, Scott W. H.; Tate, Angela M.; Rossmann, Doralyn; Hansen, Mary-Anne (2014). "The social media toll road. The promise and peril of Facebook advertising". C\&RLNews, September.

\section{Nueva colección EPI Scholar}

\section{Libros académicos y científicos de Información y Documentación}

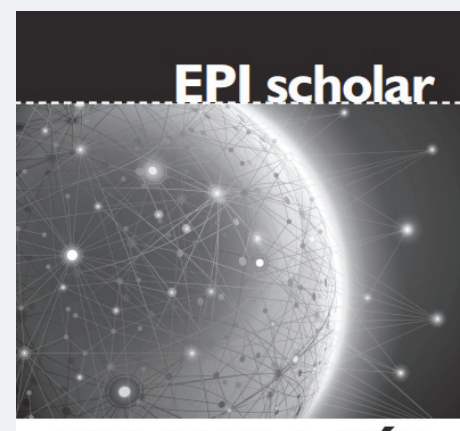

CIBERMETRÍA MIDIENDO EL ESPACIO RED ENRIQUE ORDUNA-MALEA ISIDRO F. AGUILLO

\section{Primer título:}

\section{Cibermetría. Midiendo el espacio red} de Enrique Orduña-Malea e Isidro F. Aguillo

A pesar del crecimiento de la disciplina de la Cibermetría desde mediados de la década de los noventa, son escasos los libros académicos o manuales dedicados en exclusiva a la misma desde un contexto de las ciencias de la información y documentación. Este libro pretende cubrir este claro hueco en la literatura tanto nacional como internacional. 